\title{
Analisa Proses Produksi Wheeldops PT. Morodadi Prima dengan Data Tidak Normal Menggunakan Peta Kendali Exponential Weight Moving Average (EWMA) dan Double Exponential Weight Moving Average (DEWMA)
}

\author{
Muhammad Hilmi Sasmito Adji, Soehardjoepri, dan Farida Agustini Widjajati \\ Departemen Matematika, Fakultas Matematika, Komputasi, dan Science Data, \\ Institut Teknologi Sepuluh Nopember (ITS) \\ e-mail: agustini.farida54@gmail.com
}

\begin{abstract}
Abstrak-Pengendalian kualitas dalam industri manufaktur otomotif sangat diperlukan agar produk yang dihasilkan sesuai dengan standar yang telah ditetapkan dan mampu bersaing dengan produsen lain. PT. Morodadi Prima yang memproduksi berbagai kebutuhan kendaraan roda empat, dan salah satunya adalah Wheeldops. Namun dalam produksinya, PT. Morodadi Prima belum menerapkan peta kendali statistik. Peta kendali EWMA masih jarang digunakan untuk pengendalian kualitas produk industri, selain itu DEWMA merupakan peta kendali yang merupakan turunan dari pets kendali EWMA. Produksi Wheeldops pada PT. Morodadi Prima dilakukan dengan data yang tidak normal, sehingga pada tugas akhir ini dilakukan pengkajian rumusan batas pengendali DEWMA dan EWMA untuk data tidak normal dan membandingkan hasil dan proses dari peta kendali tersebut untuk data tidak normal dalam pengendalian kualitas produk Wheeldops pada PT. Morodadi Prima. Hasil perhitungan dan perbandingan menunjukkan bahwa Peta Kendali DEWMA lebih cepat mendeteksi pergeseran data produksi Wheeldops PT. Morodadi Prima dengan data tidak normal dari pada peta kendali EWMA.
\end{abstract}

Kata Kunci-Peta Kendali EWMA dan DEWMA, Data Tidak Normal, ARL.

\section{PENDAHULUAN}

$\mathrm{P}$ ERSAINGAN industri di Indonesia saat ini semakin ketat dan luas, sehingga berdampak pada persaingan perusahaan-perusahaan menciptakan produk yang baik. Dengan adanya berbagai sumber daya yang ada, ditambah dengan teknologi yang sudah semakin canggih menyebabkan masing-masing perusahaan harus memiliki perencanaan yang baik terhadap produk yang dihasilkannya. Selain itu, perusahaan juga harus bisa memberi jaminan kualitas atas produk yang dihasilkannya pula. Dengan baiknya produk yang dihasilkan, dapat menarik minat konsumen, sehingga konsumen percaya pada produk dan perusahaan tersebut. Proses produksi adalah satu kegiatan perbaikan terus menerus yang dimulai dari sederet siklus, sejak adanya ide menghasilkan suatu produk, pengembangan produk, kegiatan produksi, sampai distribusi pada konsumen [1]. Dengan adanya kemungkinan bahwa produk yang dihasilkan tidak seluruhnya berkualitas baik, sehingga perlu dilakukan pengendalian kualitas.

Berdasarkan Standar Internasional dan Standar Nasional Indonesia, pengertian kualitas adalah keseluruhan ciri dan karakteristik produk atau jasa yang kemampuannya dapat memuaskan kebutuhan, baik yang dinyatakan secara tegas maupun tersamar. Sedangkan, pengendalian kualitas adalah aktivitas menejemen dan keteknikan yang dengan aktivitas itu perusahaan dapat mengukur ciri-ciri kualitas produk, membandingkannya dengan spesifikasi atau persyaratan dan mengambil tindakan yang sesuai apabila ada perbedaan antara penampilan yang sebenarnya dan yang standar. Tujuan pokok pengendalian kualitas secara statistika adalah menyidik dengan cepat terjadinya sebab-sebab terduga atau pergeseran proses dan tindakan pembetulan dapat dilakukan sebelum banyak unit yang tak sesuai diproduksi [2].

Peta kendali adalah alat statistik yang digunakan untuk memonitor atau memantau suatu proses serta mempelajari proses dari waktu ke waktu [3]. Peta kendali yang sering digunakan untuk pengendalian kualitas pada proses produksi secara statistik adalah peta kendali $\bar{X}$. Dalam beberapa jurnal menunjukkan bahwa peta kendali EWMA dapat digunakan untuk pengendalian pada proses produksi massal secara statistik. Selain itu ada beberapa jurnal juga menunjukkan bahwa DEWMA pun dapat digunakan untuk pengendalian kualitas dalam suatu proses produksi dengan lebih akurat menggunakan beberapa syarat.

PT. Morodadi Prima adalah salah satu perusahaan yang memproduksi berbagai jenis furnitur dan spare part untuk bis. Beberapa diantaranya adalah kursi dalam, velg, light sen, spoiler, wheeldops dll. Wheeldops merupakan salah satu spare part produksi PT. Morodadi Prima yang merupakan lempengan pelindung velg dan ban. Wheeldops terbuat dari plat baja putih atau yang biasa disebut plat SPCC (Steel Plate Cold Rolled Coiled). Plat SPCC yang berbentuk lembaran kemudian dipotong sehingga berbentuk lingkaran dengan diameter yang sudah ditentukan. Lingkaran tersebut kemudian dibentuk menjadi wheeldops dengan alat penekan atau alat press dengan tekanan depan dan belakang dengan ukuran tertentu. Produksi wheeldops PT. Morodadi Prima tidak memiliki jumlah tetap dalam sekali produksi. Ada beberapa penyebab produksi tersebut tidak memiliki jumlah yang tetap dalam sekali produksi, salah satunya adalah kebutuhan pasar. Oleh karena itu, diperlukan penerapan sistem pengendalian kualitas yang dapat menyelesaikan permasalahan tersebut. Dalam proses produksi tersebut tidak diterapkan peta kendali statistik untuk pemecahan masalah yang ada atau untuk proses pengendalian kualitasnya itu sendiri. Sehingga penerapan Statistical Quality Control $(S Q C)$ dapat digunakan untuk permasalahan tersebut. 
Beberapa penelitian sebelumnya yang berkaitan dengan pengendalian kualitas dengan peta kendali EWMA dan peta kendali DEWMA salah satunya adalah penelitian dari Chusnul Khotimah yang menerapkan peta kendali tersebut dalam analisa produksi papan kayu pada PT, Inhutani Gresik. Penelitian tersebut menggunakan data dengan distribusi normal dan selanjutnya dijadikan rujukan dan referensi dalam penelitian tentang analisa pengendalian kualitas Wheeldops pada PT. Morodadi Prima dengan data tidak normal dengan peta kendali EWMA dan DEWMA [4].

Berdasarkan latar belakang dan permasalahan tersebut, pada Tugas Akhir ini bertujuan menganalisis pengendalian kualitas produksi Wheeldops pada PT. Morodadi Prima dengan data tidak normal menggunakan metode EWMA dan DEWMA.

\section{DASAR TEORI}

\section{A.Distribusi Uniform}

Data yang berdistribusi uniform memiliki nilai peluang kejadian berhasil adalah sama pada interval [a,b] [2]. Distribusi uniform dalam interval $[a, b]$ memiliki fungsi kepadatan probabilitas $(p d f)$ adalah

$$
f(x)=\left\{\begin{array}{ll}
0 & \text { untuk } \mathrm{b}<x<a \\
\frac{1}{b-a} & \text { untuk } a \leq x \leq b
\end{array} .\right.
$$

sedangkan rata-rata $(\mu)$ dan variansi $\left(\sigma^{2}\right)$ dari data yang berdistribusi uniform adalah:

$$
\begin{aligned}
& \mu=E(X) \\
& \sigma^{2}=\operatorname{Var}(X)
\end{aligned}
$$

dengan $E(X)$ adalah nilai ekspektasi dari $X$ dan $\operatorname{Var}(X)$ adalah nilai varian dari $X$. Dengan nilai ekspektasi dan varian dari $X$ adalah sebagai berikut:

$$
\begin{aligned}
& E(X)=\frac{b+a}{2} \\
& \operatorname{Var}(X)=\frac{(b-a)^{2}}{12}
\end{aligned}
$$

dengan $b$ dan $a$ adalah interval dari data.

\section{B. Peta Kendali}

Model umum peta kendali yang ditemukan pertama kali oleh Dr. Walter A. Shewhart adalah

$$
\begin{aligned}
& B P A=E(Z)+L \sqrt{\operatorname{Var}(Z)} \\
& G T=E(Z) \\
& B P B=E(Z)-L \sqrt{\operatorname{Var}(Z)}
\end{aligned}
$$

dengan $E(Z)$ adalah ekspektasi dari $Z$ dan $\operatorname{Var}(Z)$ adalah varian dari $\mathrm{Z}$.

Sedangkan $\mathrm{Z}$ adalah variabel yang menyatakan suatu karakteristik kualitas tertentu. Sedangkan $L$ adalah koefisien lebar batas kendali. Sehingga rumusan batas kendali berdasarkan Persamaan tersebut dapat dituliskan dengan,

$$
\begin{aligned}
& B P A=\mu_{z}+L \sigma_{z} \\
& G T=\mu_{z} \\
& B P B=\mu_{z}-L \sigma_{z}
\end{aligned}
$$

dengan $\mu_{z}=$ mean dari proses $\mathrm{Z}$ dan $\sigma_{z}=$ Standart deviasi dari Z. Peta kendali EWMA merupakan pengembangan dari peta kendali $\bar{X}$.

\section{Peta Kendali EWMA}

Pertama kali dikenalkan pada tahun 1959 oleh Roberts. Peta kendali EWMA adalah peta kendali yang digunakan untuk mendeteksi pergeseran kecil mean proses. Peta kendali EWMA dapat mendeteksi pergeseran kecil dalam suatu proses produksi dan memiliki nilai pembobot untuk setiap data yang digunakan. Peta Kendali EWMA dapat didefinisikan dengan sebagai berikut:

dengan:

$$
Y_{j}=\lambda X_{j}+(1-\lambda) Y_{j-1}
$$

$\lambda$ adalah parameter pembobot EWMA dengan nilai $0<$ $\lambda \leq 1$

$Y_{j}$ adalah nilai EWMA

$X_{j}$ adalah data hasil produksi pada waktu ke $j$

$j=1,2,3, \ldots, n$

dengan $\lambda$ adalah parameter pembobot yang digunakan bernilai $0<\lambda \leq 1$, adanya $\lambda$ untuk memberikan bobot pada data awal sehingga dapat mendeteksi pergeseran data lebih 33ensitive [2]. Pada tahun 1999, Borror, Montgomery dan Runger membandingkan kinerja peta kendali EWMA dan Shewhart berdasarkan nilai ARL untuk data berdistribusi normal dan tidak normal. Dua informasi penting yang dihasilkan adalah pertama, nilai ARL untuk peta kendali shewhart dengan data tidak normal sangat kecil sehingga meningkatkan laju alarm palsu dan membuat data tidak valid. Kedua, peta kendali EWMA bekerja dengan sangat baik untuk data berdistribusi normal dan tidak normal.

Batas kendali untuk peta kendali EWMA adalah,

dengan,

$$
\begin{aligned}
& B P A=\mu_{0}+L \sqrt{\frac{\lambda}{(2-\lambda)} \sigma_{X}^{2}} \\
& G T=\mu_{0} \\
& B P B=\mu_{0}-L \sqrt{\frac{\lambda}{(2-\lambda)} \sigma_{X}^{2}}
\end{aligned}
$$

$\mu_{0}$ adalah mean dari $X_{j}$

$\sigma_{\bar{X}_{j}}^{2}$ adalah varian dari $X_{j}$

\section{Peta Kendali DEWMA}

Pada tahun 1992, Shamma S.E dan Shamma S.K melakukan penelitian mengenai peta kendali DEWMA yang merupakan pengembangan dari peta kendali EWMA. Peta kendali DEWMA dibentuk untuk meningkatkan nilai sensivitas dalam mendeteksi pergeseran nilai mean proses yang kecil. Pada umumnya, data untuk peta kendali EWMA adalah sebagai berikut:

$$
Z_{j}=\lambda Y_{j}+(1-\lambda) Z_{j-1}
$$

dengan:

$\lambda$ adalah parameter pembobot EWMA dengan nilai $0<$ $\lambda \leq 1$

$Y_{j}$ adalah nilai EWMA

$Z_{j}$ adalah nilai DEWMA

$j$ adalah subgrup dengan $j=1,2,3, \ldots, n$

Sedangkan batas kendali untuk peta kendali DEWMA adalah,

$$
\begin{aligned}
& B P A=\mu_{0}+L \sqrt{\frac{\lambda\left(\lambda^{2}-2 \lambda+2\right)}{(2-\lambda)^{3}} \sigma_{X}^{2}} \\
& G T=\mu_{0} \\
& B P B=\mu_{0}-L \sqrt{\frac{\lambda\left(\lambda^{2}-2 \lambda+2\right)}{(2-\lambda)^{3}} \sigma_{X}^{2}}
\end{aligned}
$$




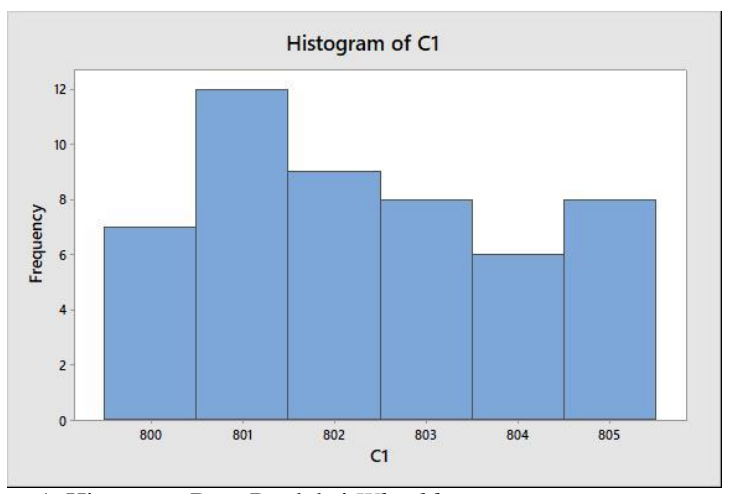

Gambar 1. Histogram Data Produksi Wheeldops.

dengan,

$\mu_{0}$ adalah mean dari $X_{j}$

$\sigma_{\bar{X}_{j}}^{2}$ adalah varian dari $X_{j}$

\section{E. Average Run Length (ARL)}

ARL merupakan rata-rata banyaknya sampel subgrup yang harus diamati sampai ditemukan out of control yang pertama. Semakin kecil nilai ARL, semakin cepat dan efektif peta kendali tersebut dalam mendeteksi adanya pergeseran proses. Nilai ARL dapat dirumuskan sebagai berikut:

$$
A R L=\frac{1}{1-\beta}
$$

dengan $\beta$ merupakan probabilitas penerimaan hasil sampling seharusnya ditolak atau cacat. Untuk mencari $\beta$ dapat dinyatakan sebagai berikut:

$$
\beta=P(B P B \leq x \leq B P A)
$$

dengan $B P A$ adalah Batas Pendali Atas dan BPB adalah Batas Pengendali Bawah.

\section{METODOLOGI PENELITIAN}

Data yang digunakan dalam penulisan Makalah ini adalah data primer pada data produksi wheeldops PT Morodadi Prima. Produk wheeldops yang digunakan adalah baja plat putih berbentuk lingkaran dengan diameter $800 \mathrm{~mm}$ dan toleransi $\geq 5 \mathrm{~mm}$. Data yang diambil berupa data diameter wheeldops pada 50 proses produksi terakhir.

Langkah-langkah analisis yang akan dilakukan berdasarkan tujuan dalam penulisan Makalah ini adalah sebagai berikut:

1. Langkah analisis untuk menyelesaikan tujuan penelitian yang pertama, yaitu mendapatkan data produksi wheeldops PT Morodadi Prima dan mencari distribusi data.

2. Langkah analisis untuk menyelesaikan tujuan penelitian yang kedua, yaitu memperoleh hasil peta kendali EWMA dan DEWMA untuk data proses produksi wheeldops PT Morodadi Prima.

a. Menerapkan peta kendali EWMA dan DEWMA berdasarkan data yang diperoleh.

b. Membandingkan hasil peta kendali EWMA dan DEWMA.

c. Menganalisa peta kendali EWMA dan DEWMA berdasarkan ARL.

\section{HASIL DAN PEMBAHASAN}

Analisis dan pembahasan mendapatkan dan membandingkan peta kendali EWMA dan peta kendali
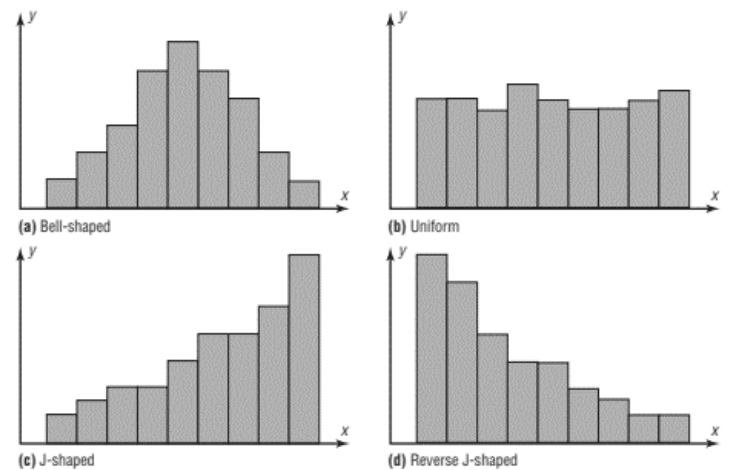

Gambar 2. Beberapa Distribusi Berdasarkan Histogram.

DEWMA untuk data produksi Wheeldops PT Morodadi Prima adalah sebagai berikut:

\section{A. Mengkaji Rumusan Batas Kendali EWMA dan DEWMA}

Digunakan plot grafik atau histogram untuk menentukan distribusi data [5]. Histogram dari data produksi wheeldops dapat dilihat pada Gambar 1:

Pada Gambar 1 disajikan histogram data produksi wheeldops dan pada Gambar 2 disajikan histogram dari beberapa distribusi. Berdasarkan Gambar 2, data produksi wheeldops termasuk pada distribusi uniform. Selain itu, karakteristik data berdistribusi uniform yaitu, memiliki interval $[a, b]$ dan data produksi wheeldops juga memiliki interval [800,805], pada distribusi uniform setiap variabelnya juga memiliki peluang berhasil antara interval [a,b] sama besar dalam suatu percobaan yang juga pada data produksi wheeldops jumlah produk yang dihasilkan memiliki peluang antara interval $[800,805]$ sama besar dalam setiap proses produksinya [3]. Sehingga karena 2 karakteristik data berdistribusi uniform juga dimiliki data produksi wheeldops, dan plot histogram dari data produksi wheeldops hampir sama dengan plot histogram dari data yang berdistribusi uniform, maka dapat dikatakan bahwa data produksi wheeldops berdistribusi uniform [5]. Dengan berdistribusi uniform, maka berdasarkan Persamaan (2) dan (3) mean dan standar deviasi dari data tersebut adalah:

$$
\begin{aligned}
\mu_{X} & =E(X)=\frac{b+a}{2} \\
& =\frac{805+800}{2} \\
& =\frac{1605}{2} \\
\mu_{X} & =802,5 \\
\sigma_{X}^{2} & =\operatorname{Var}(X)=\frac{(b-a)^{2}}{12} \\
& =\frac{(805-800)^{2}}{12} \\
& =\frac{5^{2}}{12} \\
& =\frac{25}{12} \\
& =2,083 \\
\sigma_{X} & =\sqrt{2,083} \\
\sigma_{X} & =1,4433
\end{aligned}
$$

Fungsi kepadatan probabilitas $(p d f)$ dari data produksi wheeldops yang berdistribusi uniform dari Persamaan (1) adalah

$$
f(x)=\frac{1}{805-800}=\frac{1}{5} \text { untuk } 800 \leq x \leq 805 .
$$

\section{B. Menerapkan Peta Kendali EWMA dan DEWMA}

1. Analisa Peta Kendali EWMA 
Tabel 1.

Nilai $\boldsymbol{Y}_{j}$ untuk $\boldsymbol{\lambda}=\mathbf{0 , 1}$

\begin{tabular}{cccccc}
\hline \hline No & $\bar{X}_{j}$ & $Y_{j}$ & No & $\bar{X}_{j}$ & $Y_{j}$ \\
\hline 1 & 801 & 802,35 & 26 & 800 & 802,3495 \\
2 & 804 & 802,515 & 27 & 803 & 802,4146 \\
3 & 802 & 802,4635 & 28 & 803 & 802,4731 \\
4 & 801 & 802,3172 & 29 & 804 & 802,6258 \\
5 & 803 & 802,3854 & 30 & 803 & 802,6632 \\
6 & 802 & 802,3469 & 31 & 805 & 802,8969 \\
7 & 805 & 802,6122 & 32 & 801 & 802,7072 \\
8 & 800 & 802,351 & 33 & 805 & 802,9365 \\
9 & 801 & 802,2159 & 34 & 800 & 802,6482 \\
10 & 805 & 802,4943 & 35 & 801 & 802,4786 \\
11 & 804 & 802,6499 & 36 & 803 & 802,5307 \\
12 & 802 & 802,5804 & 37 & 801 & 802,3776 \\
13 & 803 & 802,6223 & 38 & 800 & 802,1399 \\
14 & 800 & 802,3601 & 39 & 805 & 802,4259 \\
15 & 801 & 802,2241 & 40 & 801 & 802,2833 \\
16 & 802 & 802,2017 & 41 & 804 & 802,455 \\
17 & 800 & 801,9815 & 42 & 802 & 802,4095 \\
18 & 805 & 802,2834 & 43 & 801 & 802,2685 \\
No & $\bar{X}_{j}$ & $Y_{j}$ & No & $\bar{X}_{j}$ & $Y_{j}$ \\
19 & 803 & 802,355 & 44 & 805 & 802,5417 \\
20 & 802 & 802,3195 & 45 & 802 & 802,4875 \\
21 & 804 & 802,4876 & 46 & 803 & 802,5388 \\
22 & 805 & 802,7388 & 47 & 801 & 802,3849 \\
23 & 804 & 802,8649 & 48 & 802 & 802,3464 \\
24 & 801 & 802,6784 & 49 & 800 & 802,1118 \\
25 & 802 & 802,6106 & 50 & 801 & 802,0006 \\
\hline \hline & & & & & \\
\hline
\end{tabular}

Nilai masing-masing $Y_{j}$ didapatkan dari Persamaan (4) masing-masing nilai $Y_{j}$ saling berkaitan satu dengan yang lainnya. Nilai $Y_{0}$ dapat diasumsikan sebagai nilai rata-rata data atau $\mu$ [6]. Parameter yang digunakan adalah $\lambda$ dengan nilai $\lambda=0,1$ hingga $\lambda=0,5$ dengan selisih 0,1 karena ketika nilai $\lambda<0,05$ peta kendali yang dihasilkan tidak akan jauh berbeda dari peta kendali $\lambda=0,1$ dibawahnya dan ketika $\lambda \geq 0,05$ tidak akan jauh dengan beda 0,1 diatasnya.

Untuk $\lambda=0,1$

$$
\begin{aligned}
Y_{1} & =\lambda X_{1}+(1-\lambda) Y_{0} \\
& =(0,1) \bar{X}_{1}+(1-0,1) Y_{0} \\
& =(0,1)(801)+(0,9)(802.5) \\
& =80,1+722,25 \\
& =802,35 \\
Y_{2} & =\lambda X_{2}+(1-\lambda) Y_{1} \\
& =(0,1) \bar{X}_{2}+(1-0,1) Y_{1} \\
& =(0,1)(804)+(0,9)(802,35) \\
& =80,4+722,115 \\
& =802,515 \\
Y_{3} & =\lambda X_{3}+(1-\lambda) Y_{2} \\
& =(0,1) \bar{X}_{3}+(1-0,1) Y_{2} \\
& =(0,1)(802)+(0,9)(802.515) \\
& =80,2+722,2635 \\
& =802,4635
\end{aligned}
$$

melalui perhitungan yang sama untuk $j=4,5,6, \ldots, 50$ nilai $Y_{j}$ untuk $\lambda=0,1$ ditampilkan pada Tabel 1. Dengan perhitungan yang sama pula digunakan untuk menghitung $\lambda=0,2$ hingga $\lambda=0,5$.

Berdasarkan Persamaan (5), Persamaan (6) dan Persamaan (7). Setelah diperoleh Batas Kendali Atas dan Batas Kendali Bawah, dapat disusun peta kendali EWMA dengan $\lambda$ yang ditentukan untuk menampilkan data produksi wheeldops.

Pada Gambar 3 dari 50 data produksi, tidak terdapat titik yang berada diluar garis batas kendali. Hal ini menunjukkan bahwa produksi wheeldops telah terkendali secara statistik.

\section{Analisa Peta Kendali DEWMA}

Pengendalian kualitas produksi pada produk wheeldops dengan menggunakan peta kendali DEWMA dilakukan untuk
Tabel 2.

Nilai $\boldsymbol{Z}_{j}$ untuk $\boldsymbol{\lambda}=\mathbf{0}, \mathbf{1}$

\begin{tabular}{cccccc}
\hline \hline No & $\bar{X}_{j}$ & $Y_{j}$ & No & $\bar{X}_{j}$ & $Y_{j}$ \\
\hline 1 & 801 & 802,35 & 26 & 800 & 802,3495 \\
2 & 804 & 802,515 & 27 & 803 & 802,4146 \\
3 & 802 & 802,4635 & 28 & 803 & 802,4731 \\
4 & 801 & 802,3172 & 29 & 804 & 802,6258 \\
5 & 803 & 802,3854 & 30 & 803 & 802,6632 \\
6 & 802 & 802,3469 & 31 & 805 & 802,8969 \\
7 & 805 & 802,6122 & 32 & 801 & 802,7072 \\
8 & 800 & 802,351 & 33 & 805 & 802,9365 \\
9 & 801 & 802,2159 & 34 & 800 & 802,6482 \\
10 & 805 & 802,4943 & 35 & 801 & 802,4786 \\
11 & 804 & 802,6499 & 36 & 803 & 802,5307 \\
12 & 802 & 802,5804 & 37 & 801 & 802,3776 \\
13 & 803 & 802,6223 & 38 & 800 & 802,1399 \\
14 & 800 & 802,3601 & 39 & 805 & 802,4259 \\
15 & 801 & 802,2241 & 40 & 801 & 802,2833 \\
16 & 802 & 802,2017 & 41 & 804 & 802,455 \\
17 & 800 & 801,9815 & 42 & 802 & 802,4095 \\
18 & 805 & 802,2834 & 43 & 801 & 802,2685 \\
19 & 803 & 802,355 & 44 & 805 & 802,5417 \\
20 & 802 & 802,3195 & 45 & 802 & 802,4875 \\
21 & 804 & 802,4876 & 46 & 803 & 802,5388 \\
22 & 805 & 802,7388 & 47 & 801 & 802,3849 \\
23 & 804 & 802,8649 & 48 & 802 & 802,3464 \\
24 & 801 & 802,6784 & 49 & 800 & 802,1118 \\
\hline \hline
\end{tabular}

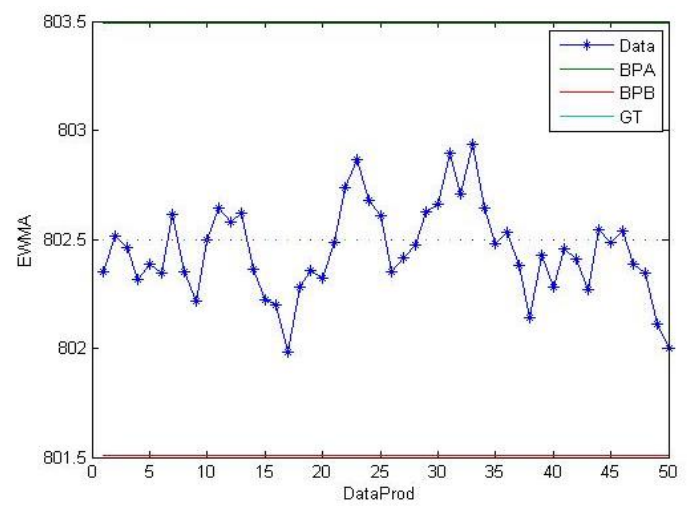

Gambar 1. Peta Kendali EWMA dengan $\boldsymbol{\lambda}=\mathbf{0}, \mathbf{1}$.

menunjukkan data hasil produksi pada produk wheeldops sudah terkendali atau belum.

Nilai $Z_{j}$ dapat diperoleh melalui Persamaan (8) dengan $Z_{0}$ yang merupakan nilai awal yang diperoleh dari rata-rata data $Z_{0}=Y_{0}=\mu_{X}$. Sehingga nilai $Z_{0}=802,5$ dan nilai standar deviasinya adalah 1,4433 . Parameter yang digunakan dalam peta kendali DEWMA adalah $\lambda=0,1$ hingga $\lambda=0,5$.

Untuk $\lambda=0,1$

$$
\begin{aligned}
Z_{1} & =\lambda Y_{1}+(1-\lambda) Z_{0} \\
& =(0,1) Y_{1}+(1-0,1) Z_{0} \\
& =(0,1)(802,35)+(0,9)(802,5) \\
& =80,235+722,25 \\
& =802,485 \\
Z_{2} & =\lambda Y_{2}+(1-\lambda) Z_{1} \\
& =(0,1) Y_{2}+(1-0,1) Z_{1} \\
& =(0,1)(802,515)+(0,9)(802,485) \\
& =80,2515+722,2365 \\
& =802,488 \\
Z_{3} & =\lambda Y_{3}+(1-\lambda) Z_{2} \\
& =(0,1) Y_{3}+(1-0,1) Z_{2} \\
& =(0,1)(802,4635)+(0,9)(802,488) \\
& =80,2464+722,2392 \\
& =802,4856
\end{aligned}
$$

dengan melakukan perhitungan yang sama, nilai $Z_{j}$ untuk $j=$ $4,5,6, \ldots, 50$ dapat ditujukkan pada Tabel 2. Dengan 
perhitungan yang sama pula digunakan untuk menghitung $\lambda=0,2$ hingga $\lambda=0,5$.

Berdasarkan Persamaan (9), Persamaan (10) dan Persamaan (11) diperoleh Batas Kendali Atas dan Batas Kendali Bawah, dapat disusun peta kendali DEWMA dengan $\lambda$ yang ditentukan untuk menampilkan data produksi wheeldops.

Pada Gambar 4 dari 50 data produksi tidak terdapat titik yang berada diluar garis batas kendali. Hal ini menunjukkan bahwa produksi wheeldops telah terkendali secara statistik.

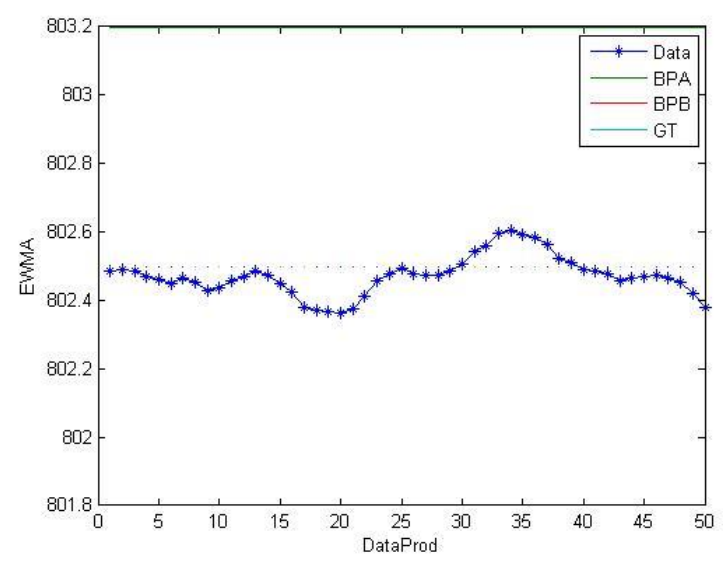

Gambar 4. Peta Kendali DEWMA dengan $\lambda=0,1$

4. Perbandingan Peta Kendali EWMA dan DEWMA

Setelah dilakukan penerapan masing-masing peta kendali terhadap data produksi wheeldops, dilakukan perbandingan kedua metode untuk menunjukkan peta kendali yang paling peka mendeteksi pergeseran proses berdasarkan ARL. Jika semakin kecil nilai ARL semakin cepat pula peta kendali mendeteksi pergeseran data. Berdasarkan Persamaan (13) nilai $\beta$ untuk $\lambda=0,1$ adalah:

$$
\begin{aligned}
\beta_{E W M A} & =P(B P B \leq x \leq B P A) \\
& =\left(\int_{801,507}^{803,493} f(x) d x\right) \\
& =\left(\int_{801,493}^{803} \frac{1}{5} d x\right) \\
& =\left(\frac{1,9896}{5}\right) \\
& =0,3972
\end{aligned}
$$

dengan melakukan perhitungan yang sama, nilai $\beta$ pada peta kendali EWMA untuk $\lambda=0,2$ hingga $\lambda=0,9$ dapat dilihat pada Tabel 3.

Tabel 3.

\begin{tabular}{cc} 
Nilai $\boldsymbol{\beta}$ peta kendali EWMA untuk $\boldsymbol{\lambda}=\mathbf{0}, \mathbf{1}$ \\
\hline \hline$\lambda$ & $\beta_{E W M A}$ \\
\hline 0,1 & 0,3972 \\
0,2 & 0,5772 \\
0,3 & 0,7276 \\
0,4 & 0,866 \\
0,5 & 1,000 \\
\hline \hline
\end{tabular}

Nilai $\beta$ untuk $\lambda=0,1$ peta kendali DEWMA berdasarkan Persamaan (13) adalah sebagai berikut:

$$
\begin{aligned}
\beta_{D E W M A} & =P(B P B \leq x \leq B P A) \\
& =\left(\int_{801,7965}^{803,2035} f(x) d x\right) \\
& =\left(\int_{801,2035}^{803} \frac{1}{5} d x\right) \\
& =\left(\frac{1,407}{5}\right) \\
& =0,2814
\end{aligned}
$$

dengan melakukan perhitungan yang sama, nilai $\beta$ pada peta kendali DEWMA untuk $\lambda=0,2$ hingga $\lambda=0,5$ dapat dilihat pada Tabel 4.
Tabel 4.

Nilai $\boldsymbol{\beta}$ peta kendali DEWMA $\boldsymbol{\lambda}=\mathbf{0}, \mathbf{1}$

\begin{tabular}{cc}
\hline \hline$\lambda$ & $\beta_{D E W M A}$ \\
\hline 0,1 & 0,2814 \\
0,2 & 0,4132 \\
0,3 & 0,5082 \\
$\lambda$ & $\beta_{D E W M A}$ \\
0,4 & 0,607 \\
0,5 & 0,7453 \\
\hline \hline
\end{tabular}

Berdasarkan Persamaan (11) nilai ARL peta kendali EWMA dengan $\lambda=0,1$ adalah,

$$
\begin{aligned}
A R L_{E W M A} & =\frac{1}{1-\beta_{E W M A}} \\
& =\frac{1}{1-0,3972} \\
& =\frac{1}{0,6028} \\
& =1,6589
\end{aligned}
$$

sedangkan nilai ARL untuk peta kendali DEWMA dengan $\lambda=0,1$ adalah,

$$
\begin{aligned}
A R L_{D E W M A} & =\frac{1}{1-\beta_{D E W M A}} \\
& =\frac{1}{1-0,2814} \\
& =\frac{1}{0,7186} \\
& =1,3916
\end{aligned}
$$

dengan perhitungan yang sama nilai ARL untuk peta kendali DEWMA dengan $\lambda=0,2$ hingga $\lambda=0,5$ dapat dilihat pada Tabel 5 .

Tabel 4 .

\begin{tabular}{ccc}
\multicolumn{3}{c}{ Nilai ARL peta kendali EWMA dan DEWMA } \\
\hline \hline$\lambda$ & $A R L_{E W M A}$ & $A R L_{D E W M A}$ \\
\hline 0,1 & 1,6589 & 1,3916 \\
0,2 & 2,3652 & 1,7042 \\
0,3 & 3,6711 & 2,0358 \\
0,4 & 7,4627 & 2,5445 \\
0,5 & - & 3,9262 \\
\hline \hline
\end{tabular}

Berdasarkan Tabel 5 karena semakin kecil nilai ARL maka akan semakin cepat peta kendali mendeteksi pergeseran proses, sehingga peta kendali DEWMA lebih cepat mendeteksi pergeseran dari pada peta kendali EWMA.

\section{V.KESIMPULAN}

Dari hasil pembahasan yang telah disajikan dapat disimpulkan:

1. Batas kendali untuk peta kendali EWMA berdasarkan data adalah,

Batas Atas Kendali $=802,5+3 \cdot(1,4433) \sqrt{\frac{\lambda}{2-\lambda}}$

Batas Bawah Kendali $=802,5+3 \cdot(1,4433) \sqrt{\frac{\lambda}{2-\lambda}}$

sedangkan batas kendali untuk peta kendali DEWMA berdasarkan data adalah,

Batas Atas Kendali $=802,5+3 \cdot(1,4433) \sqrt{\frac{\lambda\left(\lambda^{2}-2 \lambda+2\right)}{(2-\lambda)^{3}}}$

Batas Bawah Kendali $=802,5+3 \cdot(1,4433) \sqrt{\frac{\lambda\left(\lambda^{2}-2 \lambda+2\right)}{(2-\lambda)^{3}}}$

2. Penerapan peta kendali EWMA dan DEWMA untuk data produksi wheeldops PT. Morodadi Prima dengan data tidak normal menunjukkan bahwa proses produksi telah terkendali secara statistik.

3. Setelah menerapkan peta kendali EWMA dan DEWMA, untuk data produksi wheeldops PT. Morodadi Prima, berdasarkan nilai ARLnya, nilai ARL peta kendali DEWMA 
lebih kecil, hal inimenunjukkan bahwa peta kendali DEWMA lebih cepat dalam mendeteksi pergeseran proses pada data proses produksi wheeldops PT Morodadi Prima dari pada peta kendali EWMA.

\section{DAFTAR PUSTAKA}

[1] V. Gasperz, “Total Quality Management," 2004. [Online]. Available:

https://www.researchgate.net/publication/305302118_Total_Qual ity_Management. [Accessed: 27-Mar-2019].

[2] D. C. Montgomery, Design and analysis of experiments. Hoboken,
New Jersey: John Wiley \& Sons, 2009.

[3] A. Blauman, Elementary Statistics. New York: Mc Graw Hill Companies, 2009.

[4] C. Khotimah, "Analisis Peta Kendali DEWMA (Double Exponential Weight Moving Average) dalam Pengendalian Kualitas Produksi FJLB (Finger Joint Laminating Board) pada PT. Inhutani 1 Gresik," Surabaya, 2017.

[5] Montgomery and C. Douglas, Introduction to Statistical Quality Control, 6th ed. USA: John Wiley \& Sons Inc, 2009.

[6] S. S. Alkahtani, "Robustness of DEWMA versus EWMA Control Charts to Non-Normal Processes," J. Mod. Appl. Stat. Methods, vol. 12, no. 1, pp. 148-163, May 2013. 